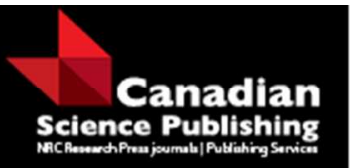

Canadian Journal of Physiology and Pharmacology Revue canadienne de physiologie et pharmacologie

\title{
Does young age really put the heart at risk?
}

\begin{tabular}{|r|l|}
\hline Journal: & Canadian Journal of Physiology and Pharmacology \\
\hline Manuscript ID & cjpp-2017-0072.R2 \\
\hline Manuscript Type: & Review \\
\hline Date Submitted by the Author: & 12-Mar-2017 \\
\hline $\begin{array}{r}\text { Complete List of Authors: } \\
\text { Is the invited manuscript for } \\
\text { consideration in a Special } \\
\text { Issue?: }\end{array}$ & $\begin{array}{l}\text { Belanger, Michael; University of Toronto } \\
\text { Wittnich, Carin; University of Toronto }\end{array}$ \\
\hline Keyword: & heart, energy, body weight, surgery \\
\hline &
\end{tabular}

SCHOLARONE ${ }^{\text {"m }}$

Manuscripts 
Does young age really put the heart at risk?

\author{
Michael Belanger, ALAT ${ }^{1}$ \\ Luke Tan, MD, $\mathrm{MSc}^{2}$ \\ Carin Wittnich, DVM, MSc ${ }^{1,2}$
}

\author{
Department of Surgery ${ }^{1}$ \\ University of Toronto \\ Toronto, Canada M5G 1L5 \\ Department of Physiology 2 \\ University of Toronto \\ Toronto, Canada M5S 1 A8
}

\begin{abstract}
ADDRESS CORRESPONDENCE TO: Dr. Carin Wittnich
University of Toronto

Medical Sciences Bldg., Rm 3260

1 King's College Circle

Toronto, Ontario Canada

M5S 1 A8

Telephone: (416) 978-7744

Fax: (416) 978-8765

c.wittnich@utoronto.ca
\end{abstract}




\begin{abstract}
Despite significant advances in the management and treatment of heart disease in children, there continue to be patients who have worse outcomes than might be expected. A number of risk factors that could be responsible have been identified. Evidence based findings will be reviewed including whether young age and/or reduced body weight exacerbate these responses. For example, newborn children undergoing congenital cardiac surgery are known to have worse outcomes than older children. Evidence exists that newborn hearts do not tolerate ischemia as well as adults; developing irreversible injury sooner and exhibiting at risk metabolic profiles. As well, in response to the administration of heparin, elevations in free fatty acids occur during congenital heart surgery in children which can have detrimental effects on the heart. Furthermore, myocardial energetic state has also been suggested to impact outcomes. Unfavorable energetic profiles were correlated to lower body weights in the same age healthy newborn piglet model. Newborn children suffering from congenital heart disease, with lower body weights, also had lower myocardial energetic state and this correlated with longer post operative ventilatory support as well as a trend to longer Intensive Care Unit stay. These findings imply that unfavorable myocardial metabolic profiles could contribute to post operative complications.
\end{abstract}

KEY WORDS: heart, energy, body weight, surgery, myocardial metabolism 


\section{INTRODUCTION}

Despite significant advances in the management and treatment of heart disease in children, there continue to be patients who have worse outcomes than might be expected. The possible reasons for this are the focus of this paper. A study in 2010 published the largest and most contemporary analysis of congenital heart disease surgical outcomes in children and reported overall annual mortality rates for children undergoing cardiac surgery as $4.1 \%$ between the years 2000-2006 (Marelli et al. 2010). Additionally, this study reported mortality rates decreasing with maturity and rising with increasing RACHS-1 (risk adjustment for congenital heart surgery) risk category (Marelli et al. 2010). Interestingly, female children demonstrated a higher in-hospital mortality rate when compared to males even after adjusting for the surgical risk category (Marelli et al. 2010). The group of Chang et al published that, after adjusting for differences in procedure risk level and age, the odds of dying were $50 \%$ higher for females than males (Chang et al. 2002). Other clinical research also reported that female gender was a risk factor for mortality of children undergoing surgery for congenital cardiac repair (Klitzner et al. 2006). Specifically, when compared with males, female children requiring mechanical cardiopulmonary support had lower survival rates, and female gender was associated with 51\% higher odds of death than males and 18\% higher-in hospital and 30day post-discharge mortality (Klitzner et al. 2006). In a newborn piglet model, hearts of females had lower baseline energy and glycogen levels compared to males, which put them at greater risk during ischemia (Wittnich et al. 2011). If this metabolic profile also occurs in children, it could be one contributor to the clinical findings reported of worse outcomes in females. In children with either cyanosis or 'High Risk' categories 4 and 5 from the Society of Thoracic Surgeons who underwent extracorporeal membrane oxygenation, the risk of stroke was higher than that in adults (Werho et al 2015). Younger children or underweight children or those with longer extracorporeal membrane oxygenation times were at greatest risk, 
independent of procedural complexity (Werho et al. 2015). It has also been identified that elevations in metabolic factors such as free fatty acids (FFA), known to be a risk factor in adults during a myocardial ischemic event, causing arrhythmias and reduced cardiac function, also has a negative impact on children undergoing congenital heart repair (Wittnich et al. 2017). The decrease in heart function was most notable when the FFA elevations were present in conjunction with cyanosis and/or prolonged ischemic time (Wittnich et al. 2017).

Additionally this elevation in FFA in neonates has been recently shown to be triggered mainly by the administration of heparin prior to the initiation of cardiopulmonary bypass and that only modest elevations were noted in response to hypoxia alone (Wittnich et al. 2017). Thus, evidence exists that neonates and infants have a higher mortality rate during cardiac surgery than adults. Furthermore, based on the limited newborn data, it seems that there is a growing trend towards females being at a disadvantage when it comes to mortality and health outcomes during cardiac surgery. Another potential predictor of worse outcomes was suggested by Werho et al., who identified that underweight children were at greater risk of stroke (Werho et al. 2015). Whether lower body weight could also serve as a predictor for worse cardiac outcomes warrants further exploration. Some evidence exists in support of this as it was reported that nutritional status, as measured by 'weight for age $Z$ ' was associated with adverse short and long term outcomes in neonates undergoing surgery for congenital heart disease (Mitting et al. 2015). Whether lower body weight has a possible connection with metabolic risk factors such as reduced antioxidant capacity or lower myocardial energy state which could, in turn, contribute to the above clinical observations, will now be examined.

Antioxidants: The fetus is exposed to low levels of oxygen during gestation implying that the need for antioxidant systems at the fetal stage is low. This is supported by the findings that fetal cells exhibit only a small fraction of the antioxidant levels that are present in adult cells (Rodrigo 2009). However, there is a major shift when the newborn makes the transition 
from intrauterine to extrauterine life, triggered in part by exposure to an extrauterine environment that is much richer in oxygen $\left(\mathrm{PO}_{2}=100 \mathrm{mmHg}\right)$ than it previously experienced in the womb $\left(\mathrm{PO}_{2}=25 \mathrm{mmHg}\right)$. Unfortunately, newborns are not equipped with the full range of antioxidants to combat this four to five fold increase in $\mathrm{PO}_{2}$ as newborn antioxidant systems are immature and inefficient. Neonatal plasma levels also demonstrate extremely low levels of the antioxidants superoxide dismutase (SOD) and glutathione peroxidase (GPx) (Rodrigo 2009). Additionally, newborns possess an increased sensitivity to free radicals and reactive oxygen species. As a result, newborns are considered high risk candidates for oxidant-mediated injury (Bandali et al 2004; Rodrigo 2009). This is supported by findings showing the production of malondialdehyde (MDA), a major end product of lipid peroxidation, at two times the rate in newborn red blood cells when compared to adults (Rodrigo 2009). Additionally, research shows that at birth, newborn blood coagulates much faster due to a marginal or deficient content of vitamin $\mathrm{E}$ in red blood cell membranes, which is said to also contribute to scavenger antioxidant deficiency in newborns (Rodrigo 2009). Studies in premature animals show that gene expression and the enzymatic activities of SOD, catalase, and GPx are significantly reduced (Rodrigo 2009). Clearly antioxidant enzyme defenses in the newborn are underdeveloped in most organs which can lead to impaired cellular metabolism, direct biomolecular damage, and structural cellular damage.

Energy state: Myocardial energetic state plays an important role in determining the success of both clinical management and treatment of infants with cardiac disease and other stresses (i.e. hypotension, restricted $\mathrm{O}_{2}$ ). Clinical studies have reported that children with lower preoperative myocardial adenosine triphosphate (ATP) have significantly impaired left ventricular function (Najm et al. 2000). This is also associated with a greater loss of ATP during ischemia and reperfusion, impaired postoperative ventricular function, and more adverse clinical outcome (Najm et al. 2000). These outcomes may also be exacerbated in the 
face of decreased levels of myocardial glycogen, as limited glycogen stores may significantly reduce tolerance of the myocardium to ischemia (Wittnich and Torrance 1994; Wittnich et al. 2011).

Interestingly, clinical studies continue to report that lower body weight is a significant risk factor associated with lower hospital survival in children undergoing repair for congenital heart disease (Gaynor et al. 2002; Stasic et al. 2006). However, whether this association is simply a factor of age of the child or related to myocardial metabolic status and energetic state remains unclear. Surgeons continue to search for simple ways of identifying myocardial energetic state in children during management and surgical treatment for congenital heart disease. There is controversy, for example, with whether young age can be used as a predictor of metabolic maturity and thus act as an indicator of outcome following surgical treatment and medical management (Bove et al. 2004; Carmosino et al. 2007; Chen et al. 2004; Hasegawa et al. 2005; Kiraly et al. 2002; Modi et al. 2004; Wernovsky et al. 2001).

As differences in myocardial energetic state are reported to be associated with postnatal development and maturation (Hearse and Riva 1989; Modi et al. 2004; Pelouch et al. 1996; Saupe et al. 2000) the question of whether infant body weight would also reflect myocardial energetic state is currently unknown and was therefore explored. We examined if a relationship exists between body weight and myocardial energetic state in a subset of children undergoing repair for congenital heart disease at the Hospital for Sick Children (Toronto, Ontario). This issue was further explored using an animal model of healthy, 3 day-old newborn piglets of varying body weights.

Children - This study was approved by the medical ethics committee at the Hospital for Sick Children. Eight acyanotic $\left(\mathrm{O}_{2}\right.$ saturation $\left.>80 \mathrm{~mm} \mathrm{Hg}\right)$ children between the ages of 4 to 21 months, ranging in weight from 3.63 to $10.3 \mathrm{Kg}$, who underwent repair for tetralogy of Fallot at the Hospital for Sick Children were studied. Right ventricular biopsies were analyzed 
for ATP and creatine phosphate (CP) ( $\mu$ moles/g dry weight) (Smolenski et al. 1990) and length of ventilatory support (hours), intensive care unit (hours) and hospital stay (days) were recorded (Table 1). Despite no correlation between body weight and myocardial ATP, there was a positive correlation between body weight and myocardial CP $\left(r^{2}=0.50, p=0.047\right)$ (Figure 1) and myocardial CP/ATP ratios $\left(r^{2}=0.55, p=0.035\right)$. Children with lower body weights also required longer periods of ventilatory support $\left(r^{2}=-0.55, p=0.035\right)$ and demonstrated a trend to longer times spent in the intensive care unit $\left(r^{2}=-0.42, \quad p=0.084\right)$ following cardiac repair. There was no significant correlation between body weight and hospital stay $\left(r^{2}=-0.34, p=0.126\right)$.

Animals - In order to isolate body weight from age or gender as the key independent variable, an animal model of healthy full term newborn 3 day - old male Yorkshire piglets $(n=25)$ ranging in weights from 1.5 to $2.3 \mathrm{~kg}$ was studied. This was done under an approved animal use protocol which conformed to the rules set out by the Guide for the Care and Use of Laboratory Animals published by the US National Institutes of Health (NIH publication No 8523, revised 1996) and the Canadian Council on Animal Care guidelines. Hearts of young pigs have been acknowledged as a very relevant model to represent human newborn hearts (Glauser 1996). Right ventricular biopsies (Belanger et al 1992) were analyzed for in vivo myocardial ATP and CP. In a smaller subset of animals $(n=12)$ myocardial glycogen $(\mathrm{MG})$ and creatine were measured (Passoneau and Lowery 1993). CP/ATP ratios, and anaerobic energy reserve $(\mathrm{AnER}=\mathrm{ATP}+\mathrm{CP}+\mathrm{MG})$ were calculated. Despite no correlations between body weight and myocardial ATP, there was a significant positive correlation between body weight and myocardial CP $\left(r^{2}=0.48, p<0.001\right)$ (Figure $\left.2 \mathrm{a}\right)$. Figures $2 \mathrm{~b}$ and c illustrate the positive correlation between body weight and creatine $\left(r^{2}=0.67, p=0.001\right)$ and $\mathrm{MG}\left(r^{2}=0.50\right.$, $p=0.01)$ respectively. The calculated CP/ATP ratios $\left(r^{2}=0.39, p<0.001\right)$ and anaerobic energy reserve $\left(r^{2}=0.47, p<0.01\right)$ also show a correlation to body weight. 
This study is the first to show, in healthy newborn piglets of the same age, a correlation between absolute body weight and myocardial $\mathrm{CP}$, creatine, and MG reserves. This suggests that within a newborn age, body weight may indeed predict myocardial energetic reserves. Newborns with lower body weights demonstrated a lower energetic state defined by lower high-energy phosphates in the form of $\mathrm{CP}$, and lower substrates used to produce usable energy, creatine and glycogen. More importantly, these results were also in part confirmed in children undergoing congenital heart surgical repair. To summarize, newborns and children with lower body weights, and thus a lower energetic state, may be at a greater metabolic risk during periods of myocardial stress such as that endured during congenital heart surgical intervention and during the use of inotropes. If so, a clinical consequence could be extended intubation times as well as longer time spent in the intensive care unit.

Body weight is strongly believed to represent a newborn's health and nutritional state. Birth weight for example evaluates maturity solely after intra-uterine growth, while postnatal measurements of body weight provide useful information about the quality and quantity of growth during both intra-uterine and early extra-uterine development (Rigo et al. 2001; Spencer 2003). As a result, body weight is one of the most common measurements used when assessing nutritional status (Rigo et al. 2001). Birth weight, and the amount of weight gained during early life has also been strongly associated with the development of a number of diseases (non-insulin dependent diabetes mellitus, coronary heart disease) and identified as risk factors for those diseases (glucose intolerance, hypertension) in early adolescent and adult life (Barker et al. 2005; Forsen et al. 2004; Harding 2001). It is reasonable therefore to suggest that body weight may in fact predict myocardial metabolic maturity and thus energetic state, particularly during the early newborn period. As shown in figure 3 , high-energy phosphates play an essential role in the normal function of the myocardium. Both human and animal studies have shown that the levels of high-energy phosphates in the myocardium are related to 
myocardial function before, during, and after periods of ischemia (Hammon et al. 1987; Riebel and Rovetto 1978). Reduced energetic reserve as indicated by low $\mathrm{CP}$ and CP/ATP ratios significantly limits cardiac performance (DeSousa et al. 1999; Gercken and Schlette 1968; Hammon et al. 1995; Liao et al. 1996; Nascimben et al. 1996; Neubauer et al. 1997; Zweier and Jacobus 1991) and tolerance to injury during a metabolic stress (Asimakis et al. 1992; De Sousa et al. 1999; Jennings et al. 1978). For example, studies in isolated rabbit hearts have shown that a $20 \%$ decrease in CP levels strongly depressed left ventricular output (Gercken and Schlette 1968). In children undergoing repair of tetralogy of Fallot, those with lower preoperative myocardial energy levels had greater loss of ATP during ischemia and reperfusion, impaired postoperative ventricular function, and more adverse clinical outcome (Najm et al. 2000). Low CP/ATP ratios are also reported to be a very sensitive predictor of mortality in patients with heart failure due to dilated cardiomyopathy (Neubauer et al. 1997). Thus any factor that may limit production of ATP during a stressful episode may significantly affect outcome during surgical management and treatment of children with congenital heart disease. ATP is regenerated from ADP via the transfer of a high-energy phosphate from CP (figure 3), thus CP is one of the first substrates utilized by the cell to maintain ATP levels during a metabolic stress. For example, low CP levels prior to an ischemic event may lead to a more rapid depletion of ATP, quicker onset of cellular injury, and thus lower ischemic tolerance. Although no relationship was found in newborn piglet between baseline myocardial ATP and body weight, this study identified a significant positive correlation between myocardial CP and body weight with animals weighing less having lower CP reserves. This possibly indicates that animals with lower body weight are either more reliant on their $\mathrm{CP}$ reserves to maintain normal ATP levels, or that these animals have a reduced ability to produce adequate $\mathrm{CP}$ reserves. Regardless of the mechanism at play, when faced with a metabolic stress such as ischemia during cardiac surgery or use of inotropes, lower body weight newborns with 
lower myocardial CP reserves may be at greater metabolic risk due to more rapid depletion of ATP levels.

The relationship between myocardial CP and body weight may also indicate differences in the maturation of creatine kinase $(\mathrm{CK})$, the enzyme responsible for the shuttling of high energy phosphates between CP and ATP (figure 3). Several studies have shown that CP levels increase with myocardial maturation, which is primarily due to the increase in total $\mathrm{CK}$ activity following birth (Pelouch et al. 1996; Saupe et al. 2000). The maturation of enzymes following birth is typically due to the presence or absence of substrate and co-factors. One of the main substrates involved in $\mathrm{CP}$ production via $\mathrm{CK}$ is creatine. Studies in sheep and mice have determined that total creatine levels in heart and skeletal muscle increase after birth, and parallel the increase in CK activity with maturity (Ingwall et al. 1981; Zandt et al. 2003). Our results indicate that, within a specific newborn piglet age ( 3 days old), body weight also correlates with myocardial creatine levels, suggesting that lower body weight newborns have a reduced capacity to produce $\mathrm{CP}$ due to lower creatine levels and possibly a more immature $\mathrm{CK}$ system. Creatine is strongly believed to regulate cardiac energetics (Wyss and KaddurahDaouk 2000) and its depletion has been shown to significantly limit the ability of the heart to increase its workload and reduce dynamics of ATP utilization (Zweier and Jacobus 1991). Taken together, the lower body weight newborns with lower $\mathrm{CP}$ and creatine levels may be less responsive to increased workload demands such as that placed on their hearts during surgical intervention.

In addition to high energy phosphate supply via the creatine phosphate shuttle, another marker of a newborn's energetic state is MG. MG represents the main stored form of glucose in the cell and is used to produce ATP via substrate-level and oxidative phosphorylation pathways (figure 3). Interestingly, with respect to maturity, glycogen levels are reported in animal studies as being high during fetal life and declining after birth (Hearse and Riva 1989). 
Our findings showed that newborns with a lower body weight had lower MG compared to heavier age-matched newborns. In this study, net MG content was measured which reflects the balance between glycogen production and consumption. It is likely that newborns with lower body weight are more dependent on glycogen stores than heavier newborns, and thus consumed more to maintain adequate ATP levels. Having lower MG reserves may significantly reduce a newborn's tolerance to low oxygen/ischemic stress as MG metabolism via anaerobic glycolysis becomes the main source of ATP production under these conditions. A previous study has demonstrated that a $70 \%$ reduction in pre-ischemic myocardial glycogen reserves resulted in a $70 \%$ and $40 \%$ decrease in the time to onset and peak ischemic contracture respectively (Gaynor et al. 2002). In this study, lower weight newborns demonstrated a similar $70 \%$ lower cardiac glycogen reserve which could thus significantly limit their heart's tolerance to any ischemic event.

Studies investigating body weight as a factor that may predict postoperative outcome are currently in disagreement. Recent retrospective analyses of low-weight infants suggest that congenital cardiac repair or palliation of several defects can be safely performed with acceptable rates of mortality and morbidity (Bove et al. 2004; Oppido et al. 2004; Reddy 2001). However, in studies focusing solely on more complex congenital defects, such as single ventricle pathologies, infants with low body weights had much lower hospital survival rates (Gayor et al. 2002; Stasic et al. 2006; Wernovsky et al. 2001). One possible explanation for this discrepancy in the literature may be that repair of complex congenital cardiac diseases requires longer cardiopulmonary-bypass and circulatory arrest times (Oppido et al. 2004). The lower weight infants may be unable to tolerate this due to their lower total anaerobic energy reserve $(\mathrm{MG}+\mathrm{ATP}+\mathrm{CP})$, representing the total amount of usable sources of energy under anaerobic conditions. This may in part be confirmed by the findings in this study in which 
children with lower body weights undergoing congenital heart surgery also demonstrated the need for longer ventilatory support and prolonged intensive care unit stay.

\section{CONCLUSION}

In addition to young age, female gender and cyanosis, body weights of children suffering from congenital heart disease that are about to undergo surgical intervention appear to reflect their myocardial energetic state. Lower body weights correlated to reduced $\mathrm{CP}$, which may significantly reduce the ability to generate ATP and affect cardiac performance during stress such as that seen during congenital heart surgery or increased workload. Therefore, compromised myocardial energetic state in children undergoing congenital heart repair may furthermore impair clinical outcomes, since those with lower body weights also required longer ventilatory support and intensive care unit stays. Even in the absence of any cardiac pathology, using a newborn animal model, body weight was a useful predictor of anaerobic myocardial energy reserves used to produce ATP. Despite having normal ATP levels, newborns with lower body weights have both reduced $\mathrm{CP}$, creatine, and $\mathrm{MG}$ reserves prior to any cardiac stress. Equipped with this knowledge, surgeons can design more effective clinical management strategies through early identification of high-risk children based on lower body weight.

\section{Acknowledgments}

The new study data included in this review, was supported by the Heart and Stroke Foundation of Ontario (T-4926). Assistance of the surgeons at the Hospital for Sick Children in the collection of biopsies and data is appreciated.

\section{REFERENCES}


Asimakis, G.K., Zwischenberger, J.B., Inners-McBride, K., Sordahl, L.A., and Conti, V.R. 1992. Postischemic recovery of mitochondrial adenine nucleotides in the heart. Circulation, 85: 2212-2220.

Bandali, K.S., Belanger, M.P., Wittnich, C. 2004. Hyperoxia causes oxygen free radicalmediated membrane injury and alters myocardial function and hemodynamics in the newborn. Am. J. Physiol. Heart Circ. 287(2): H553-H559.

Barker, D.J.P., Osmond, C., Forsén, T.J., Kajantie, E., and Eriksson, J.G. 2005. Trajectories of growth among children who have coronary events as adults. N. Engl. J. Med. 353: 1802-1809.

Belanger, M.P., Torrance, S.M., Panos, A., and Wittnich, C. 1992. Multiple in vivo fullthickness myocardial biopsies by freeze-clamping. J. Invest. Surg. 5: 143-147.

Bove,T., Francois, K., De Groote, K., Suys, B., De Wolf, D., Varhaaren, H., et al. 2004. Outcome analysis of major cardiac operations in low birth weight neonates. Ann. Thorac. Surg. 78(1): 181-187.

Carmosino, M.J., Friesen, R.H., Doran, A., and Ivy, D.D. 2007. Perioperative complications in children with pulmonary hypertension undergoing noncardiac surgery or cardiac catheterization. Anesth. Analg. 104(3): 521-527.

Chang, R-K., Chen, A.Y., and Kllitzner, T.S. 2002. Female sex as a risk factor for in-hospital mortality among children undergoing cardiac surgery. Circulation, 106: 1514-1522.

Chen, J.M., Davies, R.R., Mital, S.R., Mercando, M.L, Addonizio, L.J., Pinney, S.P., et al. 2004. Trend and outcomes in transplantation for complex congenital heart disease:1984 to 2004. Ann. Thorac. Surg. 78: 1352-1361. 
De Sousa, E., Veksler, V., Minajeva, A., Kaasik, A., Mateo, P., Mayoux, E., et al. 1999. Subcellular creatine kinase alterations: implications in heart failure. Circ. Res. 85: 6876.

Forsén, T.J., Eriksson, J.G., Osmond, C., and Barker, D.J.P. 2004. The infant growth of boys who later develop coronary heart disease. Ann. Med. 36: 389-392.

Gaynor, J.W., Mahle, W.T., Cohen, M.I., Ittenbach, R.F., DeCampi, W.M., Steven, J.M., et al. 2002. Risk factors for mortality after the Norwood procedure. Eur. J. Cardiothorac. Surg. 22: 82-89.

Gercken, G., and Schlette, U. 1968. Metabolite status of the heart in acute insufficiency due to 1-fluoro-2,4-dinitrobenzene. Experientia, 24(1): 17-19.

Glauser, E.M. 1996. Advantages of piglets as experimental animals in pediatric research. Exp. Med. Surg. 24: 181-190.

Hammon, B.L., Bittl, J.A., Jacobus, W.E., Allen, P.D., Spencer, R.S., Tian, R., et al. 1995. Inhibition of the creatine kinase reaction decreases the contractile reserve of isolated rat hearts. Am. J. Physiol. 269: H1030-H1036.

Hammon, J.W. Jr., Graham, T.P. Jr., Boucek, R.J. Jr., Parrish, M.D., Merrill, W.H., and Bender, H.W. Jr. 1987. Myocardial adenosine triphosphate content as a measure of metabolic and functional myocardial protection in children undergoing cardiac operation. Ann. Thorac. Surg. 44(5): 467-470.

Harding, J.E. 2001. The nutritional basis of the fetal origins of adult disease. Int. J. Epidemiol. 30: $15-23$.

Hasegawa, T., Yamaguchi, M., Yoshimura, N., and Okita, Y. 2005. The dependence of myocardial damage on age and ischemic time in pediatric cardiac surgery. J. Thorac. Cardiovasc. Surg. 129: 192-198.

Hearse, D.J., and Riva, E. 1989. The developing myocardium. New York, Raven Press. 
Ingwall, J.S., Kramer, M.F., Woodman, D., and Friedman, W.R. 1981. Maturation of energy metabolism in the lamb: changes in myosin ATPase and creatine kinase activities. Pediatr. Res. 15(8): 1128-1133.

Jennings, R.B., Hawkins, H.K., Lowe, J.E., Hill, M.L., Klotman, S., and Reimer, K.A. 1978. Relation between high energy phosphate and lethal injury in myocardial ischemia in the dog. Am. J. Pathol. 92: 187-214.

Kiraly, L., Hartyanszky, I., and Prodan, Z. 2002. Right ventricle failure and outcome of simple and complex arterial switch operations in neonates. Croat. Med. J. 43(6): 660-664.

Klitzner, T.S., Lee, M., Rodriguez, M.S., and Chang, R.K. 2006. Sex-related disparity in surgical mortality among pediatric patients. Congenital Heart Dis. 1: 77-88.

Liao, R., Nascimben, L., Friedrich, J., Gwathmey, J.K., and Ingwall, J.S. 1996. Decreased energy reserves in an animal model of dilated cardiomyopathy. Relationship to contractile performance. Circ. Res. 78(5): 893-902.

Marelli, A., Gauvreau, K., Landzberg, M., and Jenkins, K. 2010. Differences in mortality in children undergoing congenital heart disease surgery a United States population-based study. Circulation, 122: S234-S240.

Mitting, R., Marino, L., Macrae, D., Shastri, N., Meyer, R., and Pathan, N. 2015. Nutritional status and clinical outcome in post term neonates undergoing surgery for congenital heart disease. Pediatr. Crit. Care Med. 16(5): 448-452.

Modi, P., Suleiman, M.S., Reeves, B.C., Pawade, A., Parry, A., Angelini, G.D., et al. 2004. Basal metabolic state of hearts of patients with congenital heart disease: the effects of cyanosis, age, and pathology. Ann. Thorac. Surg. 78: 1710-1716.

Najm, H.K., Wallen, W.J., Belanger, M.P., Williams, W.G., Coles, J.G., Van Arsdell, G.S., et al. 2000. Does the degree of cyanosis affect myocardial adenosine triphosphate levels 
and function in children undergoing surgical procedures for congenital heart disease? J. Thorac. Cardiovasc. Surg. 119: 515-524.

Nascimben, L., Ingwall, J.S., Pauletto, P., Friedrich, J., Gwathmey, J.K., Saks, V., et al. 1996. Creatine kinase system in failing and nonfailing human myocardium. Circulation, 94: 1894-1901.

Neubauer, S., Horn, M., Cramer, M., Harre, K., Newell, J.B., Peters, W., et al. 1997. Myocardial phosphocreatine-to-ATP ratio is a predictor of mortality in patients with dilated cardiomyopathy. Circulation, 96: 2190-2196.

Oppido, G., Napoleone, C.P., Formigari, R., Gabbieri, D., Pacini, D., Frascaroli, G., et al. 2004. Outcome of cardiac surgery in low birth weight and premature infants. Eur. J. Cardiothorac. Surg. 26(1): 44-53.

Passoneau, J.V., Lowry, O.H. 1993. Enzymatic analysis. A practical guide. New York, Humana Press.

Pelouch, V., Kolar, F., Khuchua, Z.A., Elizarova, G.V., Milerova, M., Ostadal, B., et al. 1996. Cardiac phosphocreatine deficiency induced by GPA during postnatal development in rat. Mol. Cell. Biochem. 163-164: 67-79.

Reddy, V.M. 2001. Cardiac surgery for premature and low birth weight neonates. Semin. Thorac. Cardiovasc. Surg. Pediatr. Card. Surg. Annual. 4: 271-276.

Riebel, D.K., and Rovetto, M.J. 1978. Myocardial ATP synthesis and mechanical function following oxygen deficiency. Am. J. Physiol. 234: H620-H624.

Rigo, J., De Curtis, M., and Pieltain, C. 2001. Nutritional assessment in preterm infants with special reference to body composition. Semin. Neonatol. 6: 383-391.

Rodrigo, R. 2009. Oxidative stress and antioxidants: their role in human disease. Nova Science Publishers Inc. 
Saupe, K.W., Spindlers, M., Hopkins, J.C.A., Shen, W., and Ingwall, J.S. 2000. Kinetic, thermodynamic, and developmental consequences of deleting creatine kinase isoenzymes from the heart. J. Biol. Chem. 275(26): 19742-19746.

Spencer, N. 2003. Weighing the evidence: how is birth weight determined? Abingdon, Radcliffe Medical.

Smolenski, R.T., Lachno, D.R., Ledingham, S.J., and Yacoub, M.H. 1990. Determination of sixteen nucleotides, nucleosides and bases using high-performance liquid chromatography and its application to the study of purine metabolism in hearts for transplantation. J. Chromatogr. 527: 414-420.

Stasik, C.N., Goldberg, C.S., Bove, E.L., Devaney, E.J., and Ohye, R.G. 2006. Current outcomes and risk factors for the Norwood procedure. J. Thorac. Cardiovasc. Surg. 131: $412-417$.

Werho, D.K., Pasquali, S.K., Yu, S., Donohue, J., Annich, G.M., et al. 2015. Epidemiology of stroke in pediatric cardiac surgical patients supported with extracorporeal membrane oxygenation. Ann. Thorac. Surg. 100(5): 1751-1757.

Wernovsky, G., Rubenstein, S.D., and Spray, T.L. 2001. Cardiac surgery in the low-birth weight neonate. New approaches. Clin. Perinatol. 28(1): 249-264.

Wittnich, C., and Belanger, M.P. 2017. What factors contribute to the elevation of serum free fatty acids (FFA) in newborns in the cardiac surgical setting? Can. J. Physiol. Pharmacol. in press; DOI: 10.1139/cjpp-2016-0558.

Wittnich, C., and Torrance, S.M. 1994. Does the severity of acute hypoxia influence neonatal myocardial metabolism and sensitivity to ischemia? J. Mol. Cell. Cardiol. 26: 675-682.

Wittnich, C., Quaglietta, D., Tan, L., and Belanger M.P. 2011. Sex differences in newborn myocardial metabolism and response to ischemia. Pediatr. Res. 70: 148-152. 
Wyss, M., and Kaddurah-Daouk, R. 2000. Creatine and creatinine metabolism. Physiol. Rev. 80: 1107-1213.

Zandt, H.J.A., de Groof, A.J.C., Renema, W.K.J., Oerlemans, F.T.J., Klomp, D.W.J., Wieringa, B., et al. 2003. Presence of (phosphor)creatine in developing and adult skeletal muscle of mice without mitochondrial and cytosolic muscle creatine kinase isoforms. J. Physiol. 548(3): 847-858.

Zweier, J.L., and Jacobus, W.E. 1991. Bioenergetic consequences of cardiac phosphocreatine depletion induced by creatine analogue feeding. J. Biol. Chem. 266(30): 20296-20304.

Table 1 . Outcome parameters from subset of children undergoing repair for tetralogy of Fallot.

\begin{tabular}{|lrr|}
\hline \multicolumn{1}{|c}{ variable } & median & \multicolumn{1}{c|}{$\frac{\text { range }}{1-168}$} \\
$\begin{array}{l}\text { Ventilatory support (hours) } \\
\text { Intensive care unit stay }\end{array}$ & 44.5 & $20-190$ \\
(hours) & 6.0 & $4-23$ \\
\hline Hospital stay (days) & & \\
\hline
\end{tabular}

\section{FIGURE LEGEND}

Figure 1. Significant and positive correlation between right ventricular CP and body weight $(r=0.71, p=0.047)$ in 8 tetralogy of Fallot children.

Figure 2. (a) Significant and positive correlation between right ventricular CP and body weight in piglets $(n=25)$. (b) Significant and positive correlation between right ventricular 
creatine and body weight in piglets $(n=12)$. (c) Significant and positive correlation between right ventricular glycogen and body weight in piglets $(n=12)$.

Figure 3. Simplified diagram of key differences in myocardial energetics in newborns (bolder arrows) compared to adults. Specifically newborn hearts rely mostly on glycolysis (glucose \& glycogen) for energy production while adult hearts depend on $\beta$-oxidation (free fatty acids). $\mathrm{ADP}=$ adenosine diphosphate $\mathrm{ATP}=$ adenosine triphosphate $\mathrm{CK}=$ creatine kinase $; \mathrm{Cr}=$ creatine $; \mathrm{CP}=$ creatine phosphate $\mathrm{ETC}=$ electron transport chain $\mathrm{FFA}=$ free fatty acid; G6P = glucose - 6 - phosphate; TCA = tricarboxylic acid. 


\section{Infant CP}

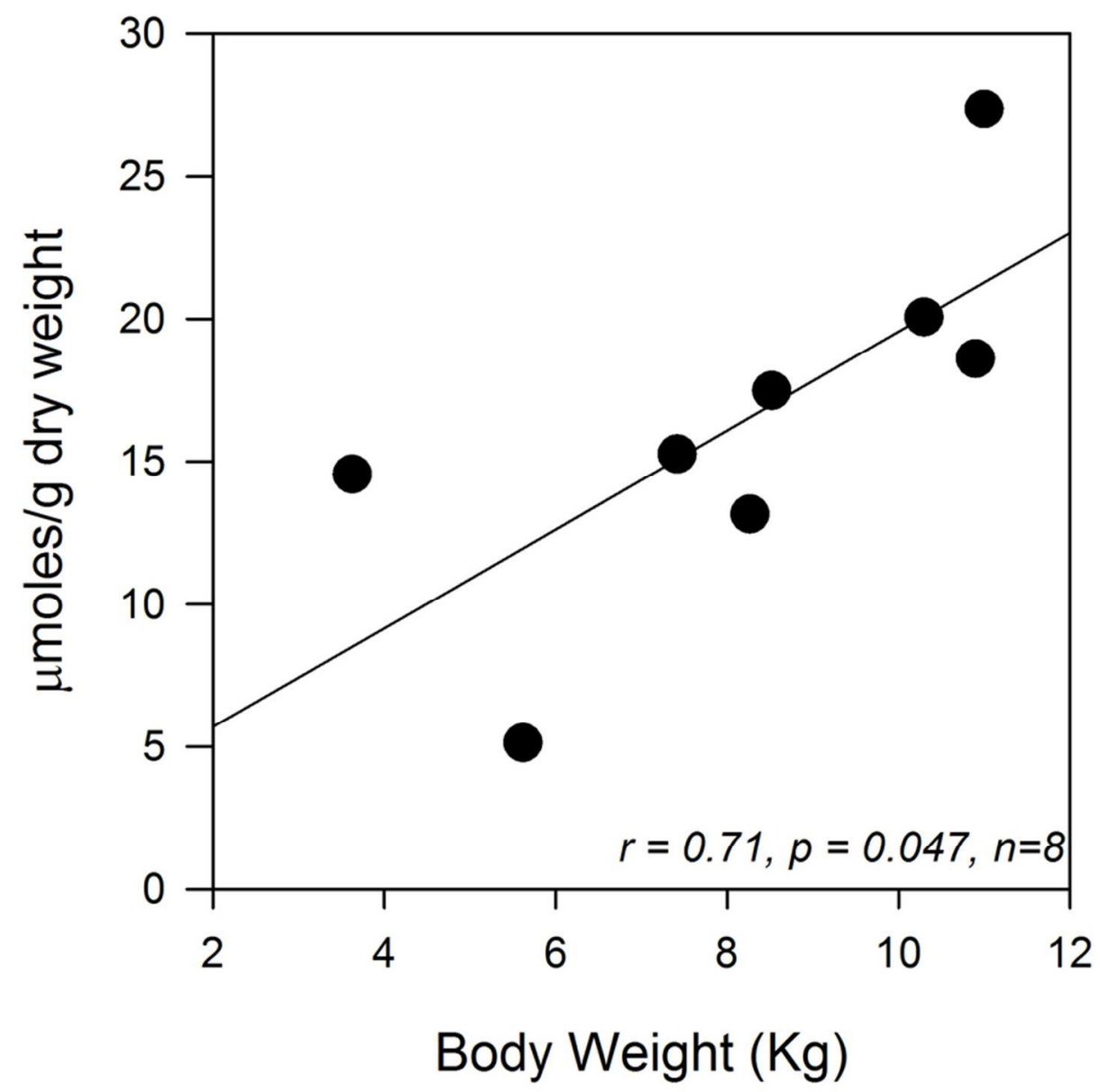

Figure 1. Significant and positive correlation between right ventricular $C P$ and body weight $(r=0.71, p=$ $0.047)$ in 8 tetralogy of Fallot children.

$81 \times 85 \mathrm{~mm}(300 \times 300$ DPI $)$ 
Figure 2a

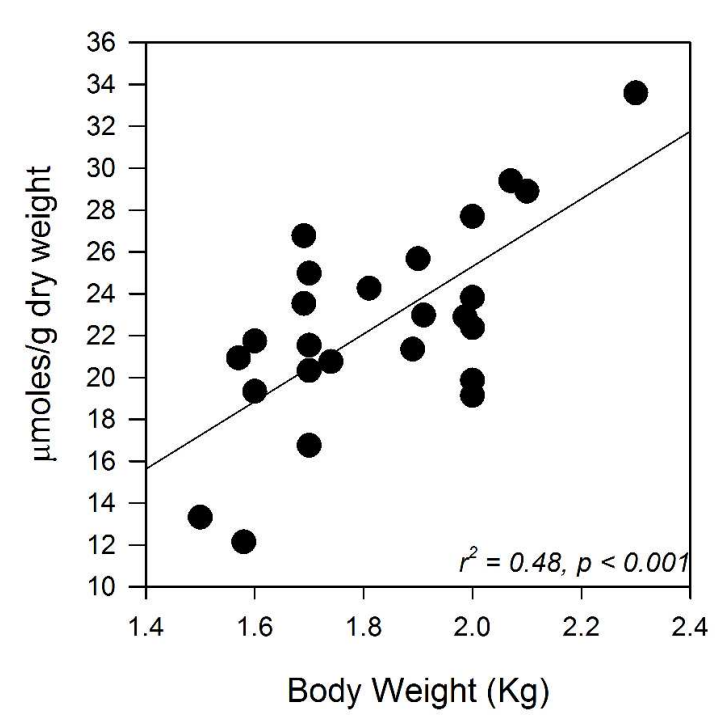

Figure $2 b$

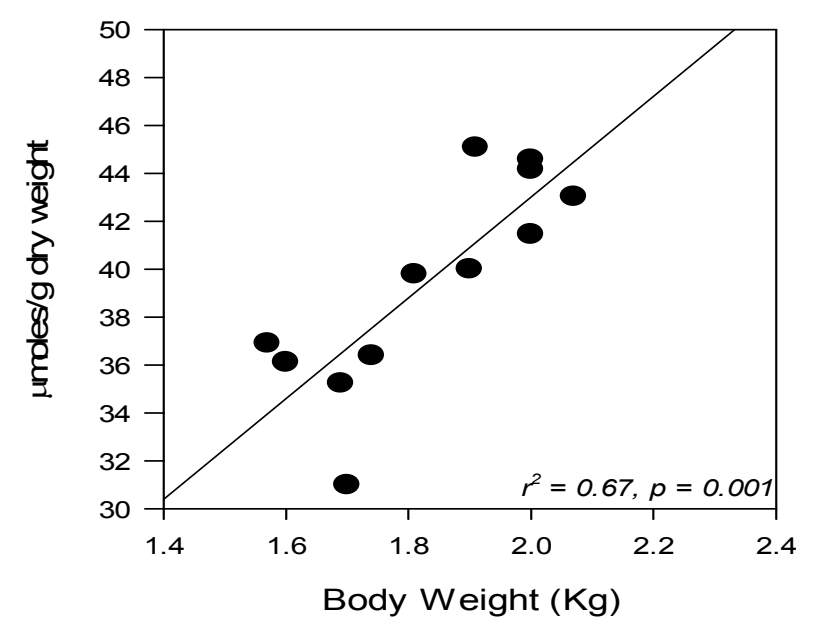

Figure 2c

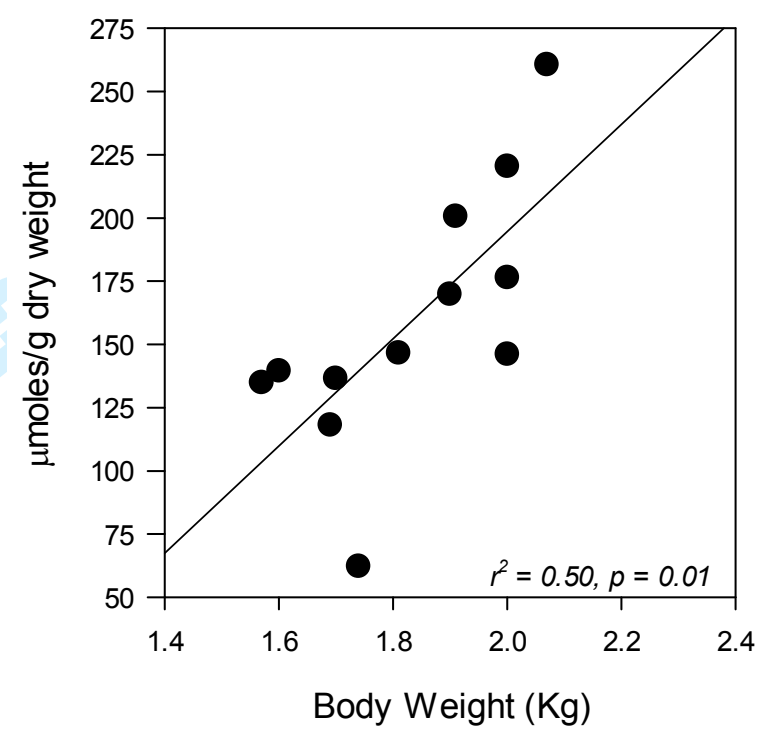




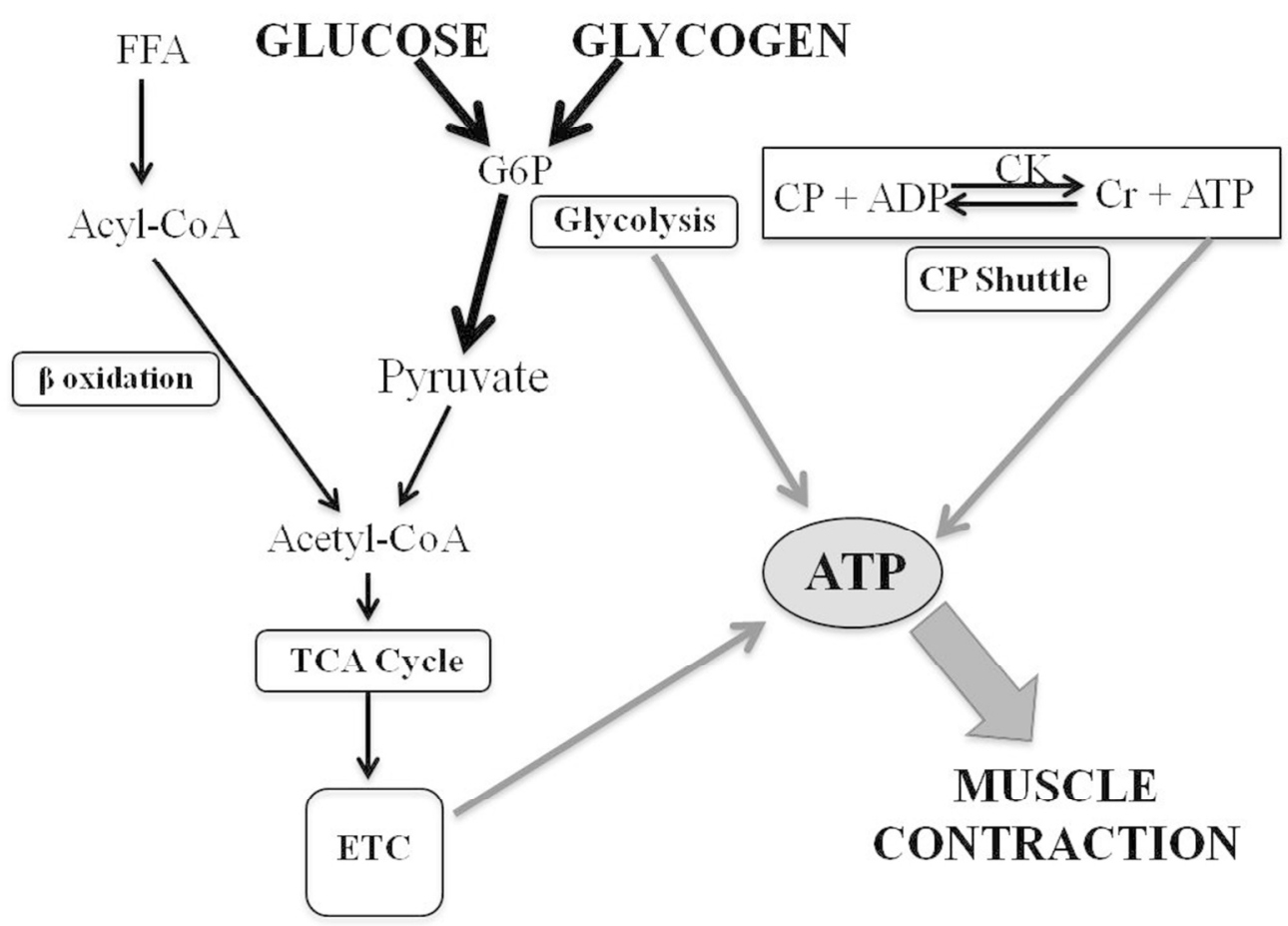

Figure 3. Simplified diagram of key differences in myocardial energetics in newborns (bolder arrows) compared to adults. Specifically newborn hearts rely mostly on glycolysis (glucose \& glycogen) for energy production while adult hearts depend on $\beta$-oxidation (free fatty acids). ADP = adenosine diphosphate; ATP $=$ adenosine triphosphate; $\mathrm{CK}=$ creatine kinase; $\mathrm{Cr}=$ creatine; $\mathrm{CP}=$ creatine phosphate; $\mathrm{ETC}=$ electron transport chain; FFA = free fatty acid; G6P = glucose -6 - phosphate; TCA = tricarboxylic acid.

$123 \times 88 \mathrm{~mm}(300 \times 300 \mathrm{DPI})$ 